The Fear of COVID-19 Familial Infection Scale: Development and Initial Psychometric Examination

Yael Mayer ${ }^{1,2^{*}}$, Shir Etgar ${ }^{3 *}$, Noga Shiffman ${ }^{4}$, Ido Lurie ${ }^{5}$

${ }^{1}$ Department of Counseling and Human Development, Faculty of Education, The University of Haifa, Israel. yaelmayer10@gmail.com

${ }^{2}$ Department of Occupational Science and Occupational Therapy, Faculty of Medicine, The University of British Columbia, Canada.

${ }^{3}$ Columbia Business School, Columbia University. Shir.etgar@gmail.com

${ }^{4}$ Rambam Health Care Campus, Haifa, Israel. Nogashiffman@gmail.com

${ }^{5}$ Shalvata Mental Health Center, Hod Hasharon, affiliated with the Sackler School of Medicine, Tel Aviv University, Ramat Aviv, Israel. Ido.lurie@gmail.com

*Authors contributed equally to the manuscript.

The current version of this paper had been published in Measurement and Evaluation in Counseling and Development, please cite:

Mayer, Y., Etgar, S., Shifman, N. \& Lurie, I. (2021), The Fear of COVID-19 Familial Infection Scale: Initial Psychometric Examination. Measurement and Evaluation in Counseling and Development. Doi: https://doi.org/10.1080/07481756.2021.1998780 
The Fear of COVID-19 Familial Infection Scale: Development and Initial Psychometric

Examination

The Fear of COVID-19 Familial Infection (FCFI) scale examines parents' fear levels of infecting their families with COVID-19. Pprinciple component analysis and confirmatory factor analysis in a sample of parents $(N=582)$ revealed two factors: Fear of infecting others and Others' Fear of being infected by me.

Keywords: COVID-19 pandemic, Fear, Stress, Parents, Healthcare workers 


\section{The Fear of COVID-19 Familial Infection Scale: Development and Initial Psychometric Examination}

The spread of the novel coronavirus disease (COVID-19) began in December 2019 in Wuhan, China, and was declared as pandemic in March 2020. The virus spreads by human-tohuman infection at a high infection rate; as of September 2020, there were 209,201,939 confirmed cases of COVID-19 worldwide, including 4,390,467 deaths, reported to the WHO (World Health Organization, 2021). It is widely accepted that pandemics take a psychological toll associated with social isolation and behavioral and emotional contagion of fear and anxiety (Huremović, 2019). For example, recent widespread outbreaks of infectious diseases such as the Severe Acute Respiratory Syndrome (SARS), Ebola, Middle East Respiratory Syndrome (MERS) and Zika resulted in various mental health consequences, including anxiety, depression, and behavioral changes (Huremović, 2019). Findings from China indicate that more than $25 \%$ of the public experienced moderate to severe levels of anxiety symptoms related to COVID-19 (Qiu et al., 2020; Wang et al., 2020). Similar rates were found during the SARS outbreak and the H1N1 pandemic (Wheaton et al., 2012).

The mental health sequelae of these outbreaks have impacted healthcare workers in particular, as a population at the forefront. A study conducted during the 2003 spread of the SARS virus in Taiwan found that at the early stages of the outbreak. in which the virus spread rapidly, healthcare personnel felt extreme vulnerability at the uncertainty and threat to their lives, which manifested as mental and physical symptoms of anxiety. After the viral outbreak was controlled, their dominant mental expression was avoidance and depression (Chong et al., 2004).

In another study involving hospital workers at the time of the SARS epidemic in Toronto ( $N=1983)$, two-thirds of the participants reported worrying about their health or their family's 
health. Living with children, lifestyle changes as a result of the virus outbreak, and a sense of stigma from the environment were associated with this concern (Nickell et al., 2004). With regard to long-term effects, about $10 \%$ of hospital staff experienced post-traumatic symptoms three years after the SARS outbreak. Healthcare workers who were in isolation, worked in departments dedicated to SARS patients, or had relatives who were infected with the virus, were 2-3 times more likely to present with severe post-traumatic symptoms (Wu et al., 2009). Considering the mental health ramifications of previous infectious disease outbreaks, it is important to investigate the adverse consequences of the current COVID-19 pandemic.

One of the main factors that increased levels of stress during the pandemic is the fear of COVID-19 (Ahorsu et al., 2020). Specifically, the fear of being infected or of transmitting the virus to one's family and friends (The Lancet, 2020). Recent literature which focused on healthcare workers and their families, stressed the need for counselors and other mental health practitioners to look beyond the healthcare workers' function as frontline responders and to consider their social roles especially as parents, partners, and offspring (The Lancet, 2020; Souadka et al., 2020).

Parenting during the pandemic is challenging for all parents; UNESCO estimated that 1.37 billion children stayed home with no childcare, group, or outdoor activities (Cluver et al., 2020). This resulted in the need for parents to find creative childcare solutions, and was especially challenging for essential workers who had to attend their work physically and at the same time. find childcare (Kalluri et al.2021). In addition, during the COVID-19 pandemic, hospital workers who were parents reported worrying about bringing the virus into their homes. They expressed concerns regarding a lack of protective equipment which put not only them but also their families at risk (Chen et al., 2020). Medical personnel in China reported mental stress 
especially if they worked in dedicated wards for COVID-19 patients in Wuhan, if they were in isolation, and if their acquaintances were infected with the virus (Dai et al., 2020).

Amidst previous pandemics such as SARS and H1N1, significant fears included fear of being infected with the disease, and fear of infecting family members and having family members who worried about being infected (Chan, 2005; Goulia 2010). This distinctive fear could be a unique characteristic of pandemics compared with other crisis situations, with a substantial impact on parents and family members who are healthcare workers or other service providers. In other types of humanitarian crises, the family is perceived by mental health professionals as the "safe haven," a protective factor from the adversity of the crises and a source of sense of safety (Gatenio-Kalush \& Cohen, 2020). In the case of COVID-19, parenting is complex, as the risk may be experienced as penetrating families' homes, creating an experience of a "threat within," followed by severe stress and emotional contagion between family members (Lateef et al., 2021).

Another important consideration in counselling and assessment is that the fear of infection may aggravate existing pre-pandemic psychiatric disorders or emotional distress and cause extreme anxiety (Colizzi et al., 2020). Studies indicated that extreme fear of COVID-19 is a predictor of posttraumatic stress (Sun et al., 2020; Xu et al., 2020). These findings highlight the importance for counselors and other mental health practitioners to reliably assess the fear of COVID-19 in order to predict mental health consequences in both the general population and in populations with psychiatric disorders. Parents with prior mental health conditions may experience difficulties in regulating their emotions (McTeague et al., 2020). Therefore, counselors' awareness of this factor is essential. 
The need for new scales to assess mental health outcomes of the ongoing pandemic, as well as future pandemics, emerged due to the pervasive mental distress and increased risk for mental illness related to the COVID-19 pandemic (Pfefferbaum \& North, 2020). To examine and assess the specific metal health outcomes of the pandemic, new measures for evaluating the fear of COVID-19 have emerged. Qiu et al. (2020) developed the COVID-19 Peritraumatic Distress Index (CPDI), a self-report scale for assessing various characteristics related to the pandemic, such as the level of social functioning, anxiety, depression and specific phobias. Recently, Ahorsu et al. (2020) developed a more concise tool to address the fear of COVID-19, called the Fear of COVID-19 Scale. This scale is comprised of 7 items which were developed based on expert evaluations and a systematic review of various fear scales. The scale includes items such as "I am most afraid of coronavirus-19" or "It makes me uncomfortable to think about coronavirus-19."

The measures that were developed thus far focus on assessing the direct, personal fear of COVID-19 (Ahorsu et. al, 2020). However, recent literature regarding healthcare workers indicates that aside from the fear of being infected with COVID-19, there is significant fear of infecting family members and having family members who worry about being infected by oneself (The Lancet, 2020; Souadka et al., 2020). This specific form of fear, that especially impacts parents, has not been assessed by other recently developed fear of COVID-19 scales.

Therefore, there is an urgent need for a complimentary measure to the existing scales which will focus on the fear of familial infection that parents who are service providers may experience. This information is necessary for counselors and mental health providers in order for them to design appropriate intervention programs to reduce familial stress. This is true especially for vulnerable populations such as frontline healthcare workers and other service providers who 
are exposed daily to the risk of being infected with COVID-19. Thus, the goal of this study was to develop and provide validity evidence for The Fear of COVID-19 Familial Infection Scale (FCFI) which will allow researchers to accumulate and evaluate data regarding this specific form of fear which is impacting parents. To achieve this goal, the current study examined two main research questions: First, what is the structure of the questionnaire, namely, how many fear factors does it address? Second, what are the psychometric characteristics of the newly developed FCFI scale and subscales? The answers to these questions will allow us to introduce this new measurement tool.

\section{Method}

\section{Participants}

Participants were parents, recruited from the general population in Israel, as well as healthcare workers with different levels of proximity and contact with COVID-19 patients. The inclusion criteria were as follows: over 18 years old, and having at least one child (to allow exploration of the scale without missing answers). The final sample included 582 parents, of whom $479(82.3 \%)$ were women and $103(17.7 \%)$ were men. Of the participants $381(65.4 \%)$ were healthcare workers. The non-healthcare workers worked in diverse professions (e.g.: academic positions, administration, education). All participants indicated that they were working at the time of the study. Of the group of healthcare workers, $218(57.2 \%)$ were medical doctors, $46(12.07 \%)$ were nurses, and $117(30.70 \%)$ were other healthcare professionals (e.g., psychologists, occupational therapists, social workers). Demographic data are presented in Table 1.

\section{Insert Table 1 about here}




\section{Procedure}

Participants were recruited via online advertisements, e-mail campaigns, blogs, social media, and text message campaigns. Participants were invited to complete the survey using the Qualtrics program. Informed consent was obtained electronically before the data were collected. All procedures conducted were approved by the Ethics Committee of the Shalvata Mental Health Center (approval number 0012-20-SHA). The survey was administered between April 15 to April 25, 2020. In Israel, the first case of COVID-19 was discovered on February 21, and the lockdown of the general population began on March 13, and was lifted gradually beginning on May 4, 2020.

\section{Development of the FCFI Scale}

To assess the levels of fear of familial infection, eight items were developed by the research team. The items were based on a literature review of the sources of fear of COVID-19 along with a review of existing COVID-19 fear scales (Ahorsu et al., 2020; Lee, 2020). In addition, self-reported information from individuals who work at the frontline and information retrieved from mass and social media were used. The items were translated to Hebrew by a native English speaker, and then back translated and compared to the English original version. The scale was administered in Hebrew.

To assess content validity, three expert healthcare professionals who also had personal experience in parenting reviewed the items. The experts were one clinical psychologist who specializes in severe psychiatric disorders, one clinical child psychologist who specializes in parental counseling and family psychology, and one psychiatrist who is an expert in working with traumatized populations and humanitarian crises. All experts have academic appointments and at least 15 years of clinical experience. The experts evaluated the face and content validity of 
the questionnaire and identified two items that were not clear or specific to fear of familial infection. "I am afraid of being infected with COVID-19" was removed because it overlapped with items from the Fear of COVID-19 Scale and was not associated with fear of infecting others. "I feel that I am being a risk for my family" was removed because the word "risk" was considered to be too general and did not directly imply the risk of infection or transmission of COVID-19.

Six items remained, and were examined using exploratory and confirmatory factor analyses. All items used 5-point Likert response options; 1- "strongly disagree," 2- "disagree," 3“neither agree nor disagree," 4- "agree," and 5- "strongly agree." Responses were averaged across items to compute composite subscale scores. Descriptive information about the items appears in Table 2.

\section{Insert Table 2 about here}

\section{Measures}

In addition to completing the FCFI, parents were asked to complete the following measures as well: (a) demographic items; (b) Fear of COVID-19 Scale; and, (c) Depressions and Anxiety Stress Scale (DASS-21). Due to the questionnaire's length in an online survey, we did not include an additional scale to measure the respondents' accuracy.

\section{Demographic items}

Parents were asked to provide demographic information such as age, gender, socioeconomic status, level of education, profession, and expertise, as well as items about their COVID-19-related characteristics such as having a pre-existing illness or exposure to a COVID19 patient.

Fear of COVID-19 scale (FCV-19S, Ahorsu et al., 2020) 
The FCV-19S is a self-report scale aimed at assessing the fear of COVID-19. The scale is comprised of seven items referring to fear responses to the pandemic (e.g.: "I worry a lot about coronavirus-19"). Participants are requested to respond on a five-point Likert-type scale ranging from 1 (strongly disagree) to 5 (strongly agree). The total score ranges between 7 to 35 , with a higher sum score indicating a higher fear of COVID-19. In a former study, scores from the measure showed adequate internal consistency reliability (Cronbach's alpha of 0.82; Ahorsu et al., 2020) and were also found to correlate with anxiety and depression, as evaluated by the Hospital Anxiety and Depression Scale (HADS, Montazeri et al., 2003) and the Perception of Others' fear of being infected by me Vulnerability to Disease Scale (PVDS, Ahmadzadeh et al. 2013). In the current study, the scale showed good internal consistency, with Cronbach's alpha of 0.84 .

\section{The Depression and Anxiety Stress Scale (DASS-21, Lovibond \& Lovibond, 1995)}

The DASS-21 is a self-report measure aimed at assessing three dimensions of mental health: depression (e.g.: "I felt that I had nothing to look forward to"), anxiety (e.g.: "I felt I was close to panic"), and stress (e.g.: "I found it difficult to relax"). Subscales are comprised of 7 items each. Participants are requested to respond on an ordinal scale ranging between 0- did not apply to me at all, 1- Applied to me to some degree, 2- Applied to me to a considerable degree to

3- applied to me very much. Composite scores were computed as the sum of the item scores. Scores for each subscale range from 0 to 21 with a higher score indicating a higher level of distress. In the current study, the DASS-21 scale showed a good internal consistency, with Cronbach's alpha of 0.93 for the total score, and Cronbach's alpha .85 for Depression, .83 for Anxiety, and .90 for Stress.

\section{Planned Analyses}


To answer the first research question, a principal component analysis (PCA) was used to examine the number of factors in the FCFI. A confirmatory factor analysis (CFA) was then applied to confirm that the model suggested by the PCA fit the data. The sample was randomly divided into two sub-samples, one used for the PCA and the other for the CFA. To answer the second research question, we examined the reliability, discriminant, divergent, and convergent validity of the FCFI. Reliability was measured using Cronbach's alpha, which measured internal consistency from 0 to 1 , with values above 0.7 suggesting sufficient reliability for research purposes. Discriminant validity was used to examine whether the FCFI can distinguish between groups predicted to have different scores. Divergent and convergent validities examine whether the FCFI is similar to scales that measure similar constructs but differ from scales that measure different constructs. Throughout the results section, the following common interpretation of effect sizes was used: for eta squared, $.01=$ small, $.09=$ medium, above $.25=$ large. For Pearson correlations, $|.1|=$ small, $|.3|=$ medium, $|.5|=$ large (Cohen, 1988). Aside from the CFA , all the analyses were conducted using SPSS V.23. The CFA was conducted using JASP 0.14.1.0.

\section{Results}

\section{Questionnaire Completion}

Twenty-nine participants (5\% of the sample) did not complete the entire set of questionnaires. These participants did not differ from those who completed the entire questionnaire in terms of their age, gender, marital status, education levels, closeness to COVID19 threat, and pre-existing conditions (all $X^{2} \mathrm{~s}<2.37$, all $p^{\prime} \mathrm{s}>.549$ ). Inclusion of their data did not change the significance of any of the analyses. Therefore, the entire dataset was used in the below analyses. 


\section{Factor Analysis and Construct Validity Evidence}

To facilitate cross-validation, the data set was randomly divided into two subsamples, one consisting of 282 participants, and the other consisting of 300

Participants.

Exploratory Factor Analysis

A principal component analysis (PCA) was conducted on the questionnaires of the subsample of 282 participants. The analysis was conducted using SPSS 23. We first carried out PCA and examined the resultant dimensionality. Two of the resultant eigenvalues exceeded one, where the first eigenvalue was 2.99 , and the second was 1.26 . There was a 0.529 eigenvalue score difference between the $2^{\text {nd }}$ and $3^{\text {rd }}$ factor, as the eigenvalue of the third factor was 0.73 . This bidimensional model accounted for $70.99 \%$ of the variance in the FCFI scores.

Because several correlations exceeded the threshold of .32 (Tabachnick \& Fidell, 2019), we conducted an oblique rotation, namely, promax (kappa $=4)$, with two factors. The item loadings are presented in Table 2. Item loadings below 0.2 were not included in the table. As can be seen, each item loaded upon one factor, therefore these two subscales can be used as-is, without deleting or modifying any item from this scale.

\section{Confirmatory Factor Analysis}

The second sub-sample of 300 participants was used for confirmatory factor analysis (CFA) using JASP 0.14.1.0. Because the residual covariance between Item 3 and Item 6 was .21, a correlation between them was added to the model. No other misfit was found in the model (all other residuals covariances $<.057)$. Good model fit resulted $(\mathrm{CFI}=0.978$; TLI= 0.953; RMSEA= 0.084; SRMR=0.024). Figure 1 represents the model.

\section{Insert Figure 1 about here}


Following the PCA and CFA, two subscales were revealed: (a) Fear of Infecting Others (FIO), included three items that address one's fear of infecting people that are close to them, such as their children or partner; (b) Perception of Others' Fear of being infected by me (POF), included three items about the fear of close others, such as the fear of infecting one's children or partner. As expected, scores from both subscales were significantly correlated $(r=.48, p<.001)$, suggesting a shared variance of $22 \%\left(r^{2}=.22\right)$. In the results that follow describing the subscales' psychometric evidence, the entire sample $(\mathrm{N}=582)$ was used.

\section{Reliability}

For research purposes, the subscale score reliabilities were adequate for the three items in the scales used (Iacobucci \& Duhachek, 2003). The score reliability for the Fear of Infecting Others (FIO) subscale was $\alpha=.79$ for those three items (items 1-3 in Table 2). The score reliability for Perception of Others' Fear of being infected by me (POF) subscale was $\alpha=.75$ for those three items (items 4-6 in Table 2).

\section{Discriminant Validity}

To explore the validity of responses across both subscales, their discriminant validity was examined. These analyses were based on the assumption that if indeed these scales represent the fear that one experiences regarding infecting their family with COVID-19, and the perception of others' fear of being infected due to their close contact with the participant. Each of these subscales would then show greater fear scores among participants with more COVID-19 risk factors. To explore this idea, two different factors that might increase one's fear and one's perception of one's family's fear were further examined: being a healthcare worker at the frontline, and having a personal or familial pre-disposition for an illness. In addition, gender 
differences were examined as a factor that most probably would not influence each of the subscales.

\section{Closeness to COVID-19 Threat}

The sample was divided into three different populations: (A) medical staff that worked with/were exposed to COVID-19 patients ("Frontliners," $n=76$ ), (B) medical staff that did not work in COVID-19 wards ("Secondliners," $n=302$ ), and (C) those who were not healthcare workers ("The comparison group," $n=188$ ). A one-way ANOVA with proximity to threat as an independent variable and the FIO subscale as a dependent variable was conducted and a significant small size effect for the type of work variable was found $(F(2,563)=6.86, p=.001$, $\left.\eta^{2}=.024\right)$, with Frontliners $(M=3.72, S D=1.02)$ and Secondliners $(M=3.53, S D=.92)$ showing higher levels of fear compared to the comparison group $(M=3.28, S D=.96)$.

Tukey HSD post-hoc tests revealed significant differences between the comparison group and the two study groups (with Secondliners, $p=.015$, CI[-.45,-.04]; and with Frontliners, $p=$ .002, CI95\%[-.74,-.13]). However the difference between front and second liners was not significant $(p=.26$, CI95\%[-.47,.09]).

An additional ANOVA with type of work as an independent variable and the POF subscale as a dependent variable was conducted, and a significant, medium-sized effect for the type of work variable (was found $F(2,563)=68.6, p<.001, \eta^{2}=.196$ ). Frontliners indicated that the levels of others' perceived fear of infection were higher $(M=2.93, S D=.90)$ compared to Secondliners $(M=2.66, S D=.91)$, who indicated higher levels of others' perceived fear compared to the comparison group $(M=1.82, S D=.80)$. Tukey HSD post-hoc tests revealed that all differences between those groups were significant (all $p$ 's $<.05$, none of the CIs include zero).

\section{Pre-Existing Conditions}


Regarding pre-existing medical conditions, it was expected that if one has, or one's family member has, a pre-existing medical condition, their fear of harming their families as well as their families' fear of being infected would be greater. To explore this assumption, participants whose spouses, children, or themselves had any type of pre-existing medical condition, were compared to those who did not.

A one-way ANOVA was conducted with pre-existing medical conditions as an independent variable and the FIO subscale as a dependent variable, yielding a significant small effect for pre-existing medical conditions in the family $\left(F(1,580)=8.73, p=.003, \eta^{2}=.015\right.$, CI95\%[-.41, -.08]), in which participants who had familial pre-existing medical conditions showed higher fear levels $(M=3.65, S D=.93)$ compared with those who did not have familial pre-existing medical conditions $(M=3.40, S D=.97)$.

An additional one-way ANOVA was conducted with pre-existing medical conditions as the independent variable and the POF subscale as the dependent variable. Similarly, a significant small effect for pre-existing medical conditions in the family was found $(F(1,580)=8.26, p=$ $.004, \eta^{2}=.014$, CI95\%[-.41, -.07]), where participants who had familial pre-existing medical conditions reported that their families experienced higher levels of fear $(M=2.58, S D=1.02)$ compared with those who had no such pre-existing conditions $(M=2.34, S D=.94)$.

\section{Gender Influences}

Gender differences were not expected, as there was no apparent reason to assume that the fear of harming one's family, and the family's fear of being infected should differ across genders. Indeed, for both scales, there was no significant effect of gender as a factor. For the FIO subscale, $F(1,580)=3.32, p=.07, \eta^{2}=.006$, CI95\%[-.01,.39]; And for the POF subscale, $F(1,580)=.218, p=.64, \eta^{2}=.000$, CI95\%[-.26,16]). 


\section{Divergent and Convergent Validity}

Divergent and convergent validities were explored, by examining to what extent responses on these scales associated with similar measurements. We first examined whether our scale converged with the fear of COVID-19 scale, a similar scale that does no specifically focus on fear of infection. As both scales measure fears of COVID-19, we expected to find correlations. We then examined the association between the FCFI subscales and DASS-21. We believe that our scale measures different structures than those measured by the DASS-21, because our scale does not focus on mental health outcomes. Therefore, we expected it to be distinct from the FCFI subscales. Correlations higher than .4 were interpreted as sufficiently converging, and lower than .2 as sufficiently diverging.

\section{Fear of COVID19 scale}

A significant and positive correlation was found between the FIO subscale and the total score of the Fear of COVID-19 scale $(r=.485, p<.001$, CI95\%[.41,.56]). This large effect size indicates that our scale measures a structure which is similar, yet not identical, to the physical and psychological threat of COVID-19. There was also a smaller yet significant correlation between the POF and the fear of COVID-19 total score $(r=.212, p<.001$, CI95\% $[.13, .29])$, again, indicating that these are related, however distinct measures.

\section{DASS-21}

Minor associations were expected between both scales and the three DASS-21 subscales. The FIO subscale was significantly and positively, though not strongly, correlated with depression $(r=.138, p=.001$, CI95\% [.06,.22]), anxiety $(r=.194, p<.001$, CI95\%[.11,.28]), and stress $(r=.176, p<.001$, CI95\%[.09,.26]), as measured by the DASS-21. The POF subscale did not correlate with any of these measurements (depression: $r=.06, p=.13$, CI95\%[-.02,.15]; 
anxiety: $r=.06, p=.14$, CI95\%[-.02,.14]; stress: $r=.04, p=.36$, CI95\%[-.04,.12]). This suggests a good distinction between our scale and the DASS-21, allowing us to assume that our scale measures different structures. These results also suggest a good distinction between our two subscales, further supporting the idea that participants could differentiate between their own fears and their families' fears of the COVID-19 threat. Thus, the participants' own self-report correlated with other self-report measurements, while their self-report regarding others did not correlate with their own self-report measurements.

\section{Discussion}

This study explored the psychometric properties of the Fear of COVID-19 Familial Infection Scale (FCFI), a newly developed scale designed to help researchers and mental health practitioners evaluate various aspects of fear of infecting family with COVID-19. The need for scales assessing different aspects of fear of COVID-19 emerged due to the widespread impact of the pandemic on the public's mental health (Qiu et al., 2020; Wang et al., 2020). Researchers and clinicians found increased fear, stress, and anxiety related to previous pandemics (Nickell et al., 2004; Wu et al., 2009), especially among vulnerable groups such as healthcare workers who experience an increased risk for infection (Kisely, et al., 2020; Mosheva et al., 2020; Spoorthy et al., 2020). The FCFI was developed to allow measurement and evaluation of these unique and newly discovered familial stress factors that are related to the pandemic. This scale will be useful in measuring this specific type of fear in future pandemics as well.

Exploratory and confirmatory factor analyses were conducted. Both confirmed the existence of a two-factor model that explains $70.99 \%$ of the variance in the scale. The FIO and POF subscales showed adequate reliability (Cronbach's Alpha of 0.79 and 0.75 , respectively) for 
research purposes. The validity of the scores in the new scale was tested in several ways. First, it was evaluated by examining how parents' COVID-19-related characteristics correlated with different levels of fear of infection. The sample was then divided into three different populations of Frontliners, Secondliners, and a comparison group, and examined the differences in their scores. A significant effect for the level of exposure at work variable on the FIO subscale was found; Frontliners and Secondliners showed higher levels of fear compared to the comparison group. As for the POF subscale, Frontliners showed higher perceived levels of their families' fear of contagion from them compared to Secondliners, who indicated higher perceived levels of families' fear of contagion from them compared to the comparison group. These significant correlations between level of exposure at work and levels of individual and familial fear of infection validated our hypothesis that these fears stem from realistic risk factors (The Lancet, 2020; Souadka et. al, 2020).

There was also a significant and medium-to-high correlation between the FIO subscale and the Fear of the COVID-19 scale score, and a smaller yet significant correlation between the POF subscale and the Fear of COVID-19 score. These correlations may reflect the complex dynamic of fear within the family unit. Parents who perceived fear from their family members might have been afraid, to some extent, which may signify emotional contagion processes during the pandemic (Huremović, 2019; Lateef et al., 2021). On the other hand, it is possible that within the family system, perceiving partner's and children's fear was a result of projection, in which family members projected their own fears onto other family members (Keller, 2019).

Interestingly, while the FIO subscale was also significantly associated with depression, anxiety and stress, the POF subscale was not. This suggests a good distinction between those two subscales. Based on these findings and the strengths of this study, namely the sample size and the 
demographic characteristics of participants which allowed validation, the Fear of COVID-19 Familial Infection Scale appears to yield both reliable and valid scores for research purposes. Implications for Counseling Practice and Research

This study has some important implications for counselors and mental health practitioners and researchers. The FCFI scale was developed based on the prevalent premise in family counseling that the family is a unit (Haefner, 2014; Minuchin, 2018), meaning that mental health outcomes should be measured with familial perspective in mind. Within this perspective, anxiety, and fear shift among family members within the basic unit of parents and children and other close family members. Emotional contagion of fear is prevalent within families, and especially in times of crises and increased stress, and therefore it is invaluable to address fears of family infection during the pandemic within counseling research and practice (Lateef et al., 2021).

Developing this perspective in future studies of the scale, it will be interesting to assess the fear of infecting one's parents, especially for youth or young adults employed as essential workers. Another application of the scale could be the measurement of emotional contagion of fears of COVID-19 infection within families. Measuring parents' and older children's fears in a longitudinal study would allow evaluation of how this fear develops within relationships between parents and children.

Future studies on COVID-19 pandemic's mental impacts could benefit from using this scale to assess this unique fear aspect among parents and the impact of such fears on parents' mental health and their ability to regulate their children's fears. The fear of familial infection could not only be used as a dependent variable but may also explain the trajectory in which the pandemic affects people, especially frontline and first-aid workers, and their families. 
Additionally, this scale may be applicable to other populations of parents who are more exposed to the infection, such as teachers and other public service providers. This scale was tested during the COVID-19 pandemic; however, it could be applicable to future pandemics as well.

Moreover, measuring the levels of this fear could help counselors in planning and implementing psychological interventions for parents and family members who are exposed at work to COVID-19 patients, or any service providers impacted by COVID-19. Identifying the intensity of this unique fear is valuable to understanding the level of impact of one's occupation on one's parenting during the pandemic. It could be helpful for counselors who work with parents exposed to COVID-19 patients in processing this unique sense of threat, addressing this unique fear, and helping clients balance their feelings concerning the risks that their work brings to their family's family life.

It is interesting that participants were able to differentiate between their own fear of infection and their perceptions of others' fear. This distinction, demonstrated by the two different subscales, may suggest that the perceptions of other family members' fear is an additional stress factor, adding to parents' mental load. This finding aligns with the family system theory that stresses the ways that anxiety and fear reside within a family unit rather than within an individual in the family (Titelman, 2012). It should also be noted that the fear of others of becoming infected by this study's participants was assessed subjectively by the participants themselves. This is not aimed to be a measure for others' stress, but rather an assessment of the perception of others' fear of being infected by participants, because of one's COVID-19 exposure. It would be important for counselors to clinically assess the actual levels of fear of these significant others and to help parents regulate their children's feelings of fear from their exposure at work.

\section{Study Limitations}


A few limitations of this study should be noted. First, the reliabilities are too low for clinical use, and are sufficient for research use only. To enhance the reliability of the scale, more items should be developed for each subscale. It should also be noted that more items and higher reliabilities might affect the association between the current scales and other scales, which, for example, may lead to higher association between the POF and the DASS-21 subscales. In addition, more test-retest studies, as well as confirmatory studies, should be conducted to assure the reliability and validity of the scale. Another limitation concerns the sample gender ratio. The sample consisted primarily of women (82\%). To generalize the results in terms of gender, cultural and ethnic background, further studies are required. Recent studies regarding the COVID-19 pandemic's impact show that not only physicians but also other service providers feel threatened, and it is important to study the mental health consequences within these populations as well. Another potential limitation is attributed to the methodology; the fear of infection was measured by self-report measures that could be affected by social desirability, which should be measured in future studies.

Future studies may also engage physiological measures such as heartrate, salivary biomarkers, and galvanic skin response (Konstantinos et al. ,2017). In this exploratory study the FCV-19S was used as the only COVID-19 fear measure, because it was the only scale that had a validated Hebrew translation at the time of the administration of the survey. To further test convergent validity, the FCFI could be compared to several additional instruments that have been developed to measure COVID fear (e.g., the COVID Stress Scales, Taylor et al., 2020). Future studies should also conduct additional confirmatory factor analysis, studies of measurement invariance, and evaluations of convergent validity with additional scales and constructs. Studies that validate scores from the scale in the English language are also needed. 
Despite these limitations, this preliminary validation of the FCFI supports the value of this scale, as well as emphasizes its applications in counseling research settings.

*The Authors have no competing interests to disclose.

*This study was not funded.

*Any supplementary materials needed will be provided on request. 


\section{References}

Ahorsu, D. K., Lin, C. Y., Imani, V., Saffari, M., Griffiths, M. D., \& Pakpour, A. H. (2020). The Fear of COVID-19 Scale: Development and initial validation. International Journal of Mental Health and Addiction, 1-9. Advance online publication. https://doi.org/10.1007/s11469-020-00270-8

Ahmadzadeh, M., Ghamarani, A., Samadi, M., Shamsi, A., \& Azizollah, A. (2013). The investigation of validity and reliability of a scale of perceived vulnerability to disease in Iran. British Journal of Social Sciences, 1(4), 43-51. https://doi.org/10.13140/2.1.1370.1122

Chan, S. S., Leung, G. M., Tiwari, A. F., Salili, F., Leung, S. S., Wong, D. C., \& Lam, T. H. (2005). The impact of work-related risk on nurses during the SARS outbreak in Hong Kong. Family \& Community Health, 28(3), 274-287. https://doi.org/10.1097/00003727-200507000-00008

Chen, Q., Liang, M., Li, Y., Guo, J., Fei, D., Wang, L., \& Wang, J. (2020). Mental health care for medical staff in China during the COVID-19 outbreak. The Lancet Psychiatry, 7(4), e15-e16. https://doi.org/10.1016/S2215-0366(20)30046-8

Chong, M. Y., Wang, W. C., Hsieh, W. C., Lee, C. Y., Chiu, N. M., Yeh, W. C., \& Chen, C. L. (2004). Psychological impact of severe acute respiratory syndrome on health workers in a tertiary hospital. The British Journal of Psychiatry, 185(2), 127-133. https://doi.org/10.1192/bjp.185.2.127

Cluver, L., Lachman, J. M., Sherr, L., Wessels, I., Krug, E., Rakotomalala, S., Blight, 
S., Hillis, S., Bachman, G., Green, O., Butchart, A., Tomlinson, M., Ward, C. L., Doubt, J., \& McDonald, K. (2020). Parenting in a time of COVID-19. The Lancet, 395(10231). https://doi.org/10.1016/S0140-6736(20)30736-4.

Cohen, J. (1988). Statistical power analysis for the behavioral sciences (2nd ed.). Lawrence Erlbaum Associates.

Colizzi, M., Bortoletto, R., Silvestri, M., Mondini, F., Puttini, E., Cainelli, C., \& Zoccante, L. (2020). Medically unexplained symptoms in the times of COVID-19 pandemic: A case-report. Brain, Behavior, \& Immunity-Health, 100073. https://doi.org/10.1016/j.bbih.2020.100073

Dai, Y., Hu, G., Xiong, H., Qiu, H., \& Yuan, X. (2020). Psychological impact of the coronavirus disease 2019 (COVID-19) outbreak on healthcare workers in China. https://www.medrxiv.org/content/10.1101/2020.03.09.20033498v1.full.pdf

Gatenio-Kalush, M., \& Cohen, E. (2020). Creating “a safe haven”: Emotionregulation strategies employed by mothers and young children exposed to recurrent political violence. Journal of Child and Adolescent Trauma, 13(4), 493-503. https://doi.org/10.1007/s40653-019-00299-5

Goulia, P., Mantas, C., Dimitroula, D., Mantis, D., \& Hyphantis, T. (2010). General hospital staff worries, perceived sufficiency of information and associated psychological distress during the A/H1N1 influenza pandemic. BMC Infectious Diseases, 10(1), 1-11. https://doi.org/10.1186/1471-2334-10-322

Haefner, J. (2014). An application of Bowen family systems theory. Issues in Mental Health Nursing, 35(11), 835-841. https://doi.org/10.3109/01612840.2014.921257

Huremović, D. (Ed.). (2019). Psychiatry of pandemics: A mental health response to 
infection outbreak. Springer.

Iacobucci, D., \& Duhachek, A. (2003). Advancing alpha: Measuring reliability with confidence. Journal of Consumer Psychology, 13(4), 478-487. https://doi.org/10.1207/S15327663JCP1304_14

Kalluri, N., Kelly, C., \& Garg, A. (2021). Child care during the COVID-19 pandemic: A bad situation made worse. Pediatrics, 147(3). https://doi.org/10.1542/peds.2020-041525

Keller, M. N. (2019). Bowen theory: 49A systems model for family research. In Handbook of Bowen family systems theory and research methods (pp. 49-61). Routledge.

Kisely, S., Warren, N., McMahon, L., Dalais, C., Henry, I., \& Siskind, D. (2020). Occurrence, prevention, and management of the psychological effects of emerging virus outbreaks on healthcare workers: rapid review and meta-analysis. BMJ (Clinical research ed.), 369, m1642. https://doi.org/10.1136/bmj.m1642

Konstantinos, G., Larentzakis, A., \& Papavassiliou, A. G. (2017). Surgeons' and surgical trainees' acute stress in real operations or simulation: A systematic review. The Surgeon, 15(6), 355-365. https://doi.org/10.1016/j.surge.2017.06.003

Lateef, R., Alaggia, R., \& Collin-Vézina, D. (2021). A scoping review on psychosocial consequences of pandemics on parents and children: Planning for today and the future. Children and Youth Services Review, 106002. https://doi.org/10.1016/j.childyouth.2021.106002

Lee, A. L. (2020) Coronavirus Anxiety Scale: A brief mental health screener for COVID-19 related anxiety, Death Studies, 44(7), 393-401. https://doi.org/10.1080/07481187.2020.1748481 
Lovibond, P. F., \& Lovibond, S. H. (1995). The structure of negative emotional states: Comparison of the Depression Anxiety Stress Scales (DASS) with the Beck Depression and Anxiety Inventories. Behaviour Research and Therapy, 33(3), 335-343. https://doi.org/10.1016/0005-7967(94)00075-u

McTeague, L. M., Rosenberg, B. M., Lopez, J. W., Carreon, D. M., Huemer, J., Jiang, Y., Chick, C. F., Eickhoff, S. B., \& Etkin, A. (2020). Identification of common neural circuit disruptions in emotional processing across psychiatric disorders. American Journal of Psychiatry, 177(5), 411-421. https://doi.org/10.1176/appi.ajp.2019.18111271

Minuchin, S. (2018). Families and family therapy. Routledge. https://doi.org/10.4324/9780203111673

Montazeri, A., Vahdaninia, M., Ebrahimi, M., \& Jarvandi, S. (2003). The Hospital Anxiety and Depression Scale (HADS): Translation and validation study of the Iranian version. Health and Quality of Life Outcomes, 1(1), 14. https://doi.org/10.1186/1477$7525-1-14$

Mosheva, M., Hertz-Palmor, N., Dorman Ilan, S., Matalon, N., Pessach, I. M., Afek, A., Pessach, M., Afek, A., Ziv, A., Kreiss, Y., Gross, R., \& Gothelf, D., (2020). Anxiety, pandemic-related stress and resilience among physicians during the COVID-19 pandemic. Depression and Anxiety. Advance online publication. https://doi.org/10.1002/da.23085

Nickell, L. A., Crighton, E. J., Tracy, C. S., Al-Enazy, H., Bolaji, Y., Hanjrah, S., \& Upshur, R. E. (2004). Psychosocial effects of SARS on hospital staff: Survey of a large tertiary care institution. Canadian Medical Association Journal, 170(5), 793-798. https://doi.org/10.1503/cmaj.1031077 
Pfefferbaum, B., \& North, C. S. (2020). Mental health and the COVID-19 pandemic. New England Journal of Medicine, 383, 510-512. https://doi.org/10.1056/NEJMp2008017

Qiu, J., Shen, B., Zhao, M., Wang, Z., Xie, B., \& Xu, Y. (2020). A nationwide survey of psychological distress among Chinese people in the COVID-19 epidemic: Implications and policy recommendations. General Psychiatry, 33(2), e100213. https://doi.org/10.1136/gpsych-2020-100213

Spoorthy, M. S., Pratapa, S. K., \& Mahant, S., (2020). Mental health problems faced by healthcare workers due to the COVID-19 pandemic-A review. Asian Journal of Psychiatry, 51, 102119. https://doi.org/10.1016/j.ajp.2020.102119

Souadka, A., Essangri, H., Benkabbou, A., Amrani, L., \& Majbar, M. A. (2020). COVID-19 and healthcare worker's families: Behind the scenes of frontline response. EClinicalMedicine, 23, 100373. https://doi.org/10.1016/j.eclinm.2020.100373

Sun, L., Sun, Z., Wu, L., Zhu, Z., Zhang, F., Shang, Z., \& Liu, N. (2020). Prevalence and risk factors of acute posttraumatic stress symptoms during the COVID-19 outbreak in Wuhan, China. https://www.medrxiv.org/content/10.1101/2020.03.06.20032425v1.full.pdf

Tabachnick, B. G., \& Fidell, L. S. (2019). Using multivariate statistics (7th ed.). Pearson Education.

Taylor, S., Landry, C., Paluszek, M., Fergus, T. A., Mckay, D., \& Asmundson, G. J. G. (2020). Development and initial validation of the COVID Stress Scales. Journal of Anxiety Disorders, 72, 102232. https://doi.org/10.1016/j.janxdis.2020.102232

The Lancet. (2020). COVID-19: Protecting health-care workers. The Lancet, 395, 
922.

Titelman, P. (2012). Triangles: Bowen family systems theory perspectives. Routledge.

Wang, C., Pan, R., Wan, X., Tan, Y., Xu, L., Ho, C. S., \& Ho, R. C. (2020).

Immediate psychological responses and associated factors during the initial stage of the 2019 coronavirus disease (COVID-19) epidemic among the general population in China. International Journal of Environmental Research and Public Health, 17(5), 1729. https://doi.org/10.3390/ijerph17051729

Wheaton, M.G, Abramowitz, J.S., Berman, N.C., Fabricant, L.E., \& Olatunji, B.O (2012). Psychological predictors of anxiety in response to the H1N1 (swine flu) pandemic. Cognitive Therapy and Research, 36, 210-218. https://doi.org/10.1007/S10608-011$9353-3$

World Health Organization (2021). Coronavirus disease 2019 (COVID-19): Weekly epidemiological update Coronavirus disease 2019 (COVID-19). https://www.who.int/emergencies/diseases/novel-coronavirus-2019/situation-reports

Wu, P., Fang, Y., Guan, Z., Fan, B., Kong, J., Yao, Z., Liu, X., Fuller, C. J., Susser, E., Lu, J., \& Hoven, C. W. (2009). The psychological impact of the SARS epidemic on hospital employees in China: Exposure, risk perception, and altruistic acceptance of risk. The Canadian Journal of Psychiatry, 54(5), 302-311. https://doi.org/10.1177/070674370905400504

Xu, Z., Shi, L., Wang, Y., Zhang, J., Huang, L., Zhang, C., Liu, S., Zhao, P., Liu, H., Zhu, L., Tai, Y., Bai, C., Gao, T., Song, J., Xia, P., Dong, J., Zhao, J., \& Wang, F. S. (2020). Pathological findings of COVID-19 associated with acute respiratory distress 
syndrome. The Lancet: Respiratory Medicine, 8(4), 420-422.

https://doi.org/10.1016/S2213-2600(20)30076-X 


\section{Figure 1}

A confirmatory factor analysis solution

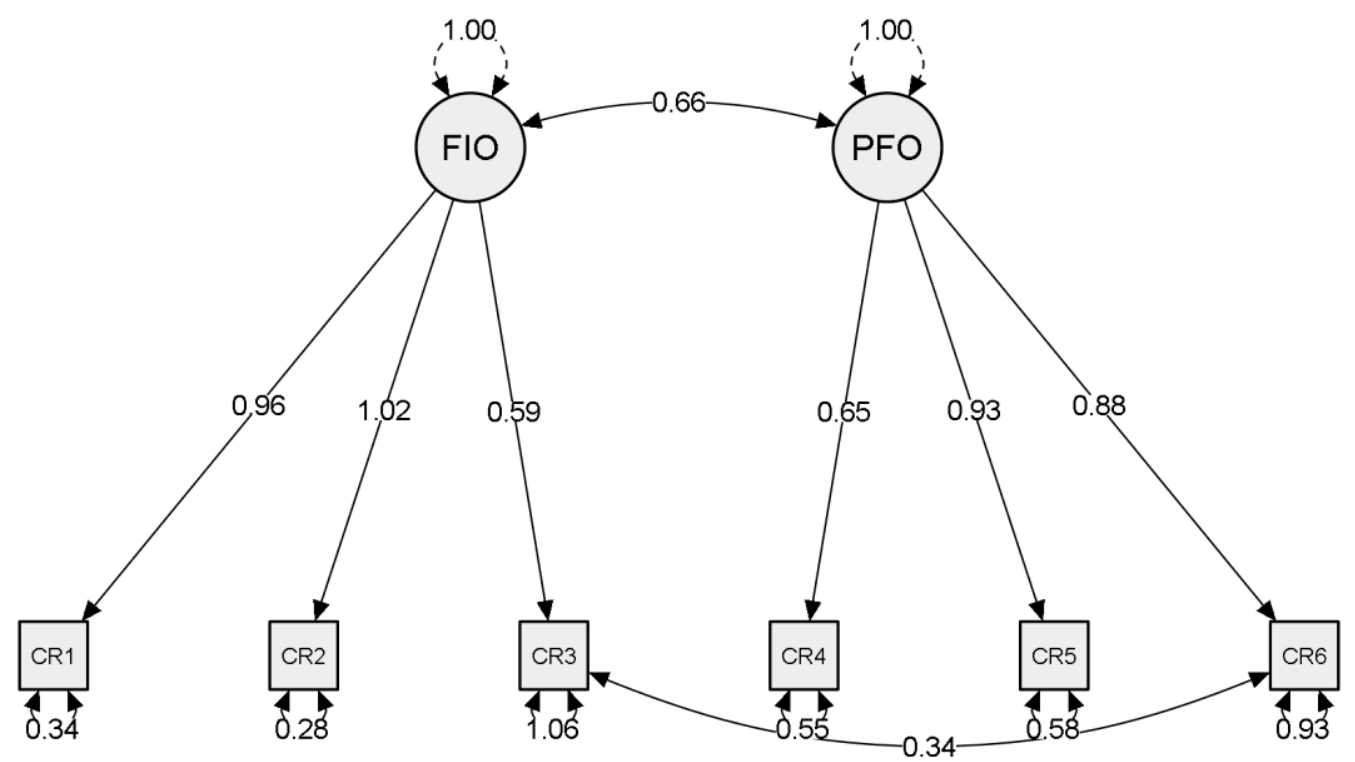

Note. $N=300$ 


\section{Table 1.}

Demographic characteristics and COVID-19 background characteristics of the sample $(N=582)$

\begin{tabular}{|c|c|}
\hline $\begin{array}{l}\text { Demographic } \\
\text { characteristics }\end{array}$ & $\mathbf{N}(\%)$ \\
\hline \multicolumn{2}{|l|}{ Gender } \\
\hline Female & $479(82.3 \%)$ \\
\hline Male & $103(17.7 \%)$ \\
\hline \multicolumn{2}{|l|}{ Age } \\
\hline Below 30 & $25(4.3 \%)$ \\
\hline $31-40$ & $260(44.7 \%)$ \\
\hline $41-50$ & $168(28.9 \%)$ \\
\hline $51-60$ & $89(15.3 \%)$ \\
\hline 61 and above & $40(6.9 \%)$ \\
\hline \multicolumn{2}{|l|}{ Marital status } \\
\hline Living with partner & $37(6.4 \%)$ \\
\hline Married & $545(93.6)$ \\
\hline \multicolumn{2}{|l|}{ Education level } \\
\hline Highschool level & $29(5 \%)$ \\
\hline Secondary school & $124(21.3 \%)$ \\
\hline Grad school & $186(32 \%)$ \\
\hline $\mathrm{MD} / \mathrm{PhD}$ and up & $243(41.8 \%)$ \\
\hline \multicolumn{2}{|l|}{ Socioeconomic level } \\
\hline Below average & $79(13.6 \%)$ \\
\hline Average & $107(18.4 \%)$ \\
\hline Above average & $396(68 \%)$ \\
\hline \multicolumn{2}{|l|}{ Background diseases } \\
\hline $\begin{array}{l}\text { Self background } \\
\text { diseases exist }\end{array}$ & $96(16.5 \%)$ \\
\hline $\begin{array}{l}\text { Spouse background } \\
\text { disease }\end{array}$ & $113(19.4 \%)$ \\
\hline $\begin{array}{l}\text { Children's background } \\
\text { disease }\end{array}$ & $44(7.6 \%)$ \\
\hline I had COVID-19 & $4(0.7 \%)$ \\
\hline
\end{tabular}


THE FEAR OF COVID-19 FAMILIAL INFECTION SCALE

\section{Table 2.}

Items' descriptive characteristics and loadings

\begin{tabular}{|c|c|c|c|c|}
\hline Items in English & Items in Hebrew & M (SD) & Factor I & Factor II \\
\hline $\begin{array}{l}\text { 1. I am afraid to infect my children with } \\
\text { the coronavirus- } 19 \text {. }\end{array}$ & 1. הקורונה. מפחד/ת להדביק את ילדיי בוירוס & $3.19(1.115)$ & .880 & \\
\hline $\begin{array}{l}\text { 2. I am afraid to infect my partner with } \\
\text { the coronavirus- } 19 \text {. }\end{array}$ & הקורונה. & $3.43(1.145)$ & .886 & \\
\hline $\begin{array}{l}\text { 3. I am afraid to infect my extended } \\
\text { family members with the coronavirus- } \\
19 .\end{array}$ & 3מורחבת שלי בוירוס הקורונה. & $3.93(1.156)$ & .793 & \\
\hline $\begin{array}{l}\text { 4. Due to the nature of my work, my } \\
\text { children are afraid that I will transmit } \\
\text { the coronavirus-19 to them. }\end{array}$ & חוששים שאדביק אותם בוירוס הקורונה. & $2.13(1.040)$ & & .852 \\
\hline $\begin{array}{l}\text { 5. Due to the nature of my work, my } \\
\text { partner is afraid that I will transmit the } \\
\text { coronavirus-19 to him/her/them. }\end{array}$ & שלי חוששים שאדל האופי של העבודה שלי, בץ/בת הזוג אותם בוירוס הקורונה. & $2.37(1.236)$ & & .876 \\
\hline $\begin{array}{l}\text { 6. Due to the nature of my work, my } \\
\text { extended family members are afraid that } \\
\text { I will transmit the coronavirus-19 to } \\
\text { them. }\end{array}$ & 6מורחבת שלי חוששים שאדביק אותי העבודה שלי, חברי המשפחה בוירוס & $2.87(1.330)$ & & .748 \\
\hline
\end{tabular}


Note. $N=282$, factors loading <.02 are not presented. Factor I: Fear of infecting others (FIO), Factor II: Perception of other's fear of being infected by me (POF). The participants indicate their level of agreement with the statements using a five-item Likert scale. Answers include "strongly disagree," "disagree," "neither agree nor disagree," agree," and "strongly agree". The minimum score possible for each question is 1 , and the maximum is 5 . In the current paper, we used the means to calculate the score for each subscale. 